\title{
Using students' reflection in the university educational process - a qualitative approach
}

\author{
Carmen Maria Țîru
}




\title{
Using students' reflection in the university educational process - a qualitative approach
}

\author{
Carmen Maria Țîru ${ }^{\mathrm{a}^{*}}$ \\ ${ }^{a}$ West University of Timișoara, Teacher Training Department, B-dul Vasile Pârvan No 4, Timișoara, 300223, Romania. \\ *Corresponding author: carmen.tiru@e-uvt.ro
}

\section{Abstract}

\section{Keywords:}

self-learning; self-assessment; feedback; self-reflection; learning journal.
The university learning process must be self-planned, self-directed, self-initiated, and frequently individually completed. To be able to achieve these goals, the students must have certain knowledge and skills. One of these is the reflective ability, developed through different modalities and using different tools. This article presents a qualitative interpretation of the students' responses written in a reflective journal, at the end of a semester, as a tool for self-assessment and self-reflection and feedback on the educational activities in which they were involved. We present, anonymously, the dominant answers for each item grouped in reflective dimensions about the teaching and learning process. Based on these responses, we tried to identify characteristics and/or difficulties in the teaching and learning process, not only to summarize and analyze but to value and/or optimize them in the future university educational process.
Zusammenfasung

Schlüsselworte:

Selbstlernen; Selbstbewertung; Feedback; Selbstreflexion; Lernjournal.
Der universitäre Lernprozess muss individuell zu einer selbstgeplanten, selbstgesteuerten, oft selbstinitiierten und häufig abgeschlossenen Lernaktivität werden. Um diese Ziele zu erreichen, müssen die Studierenden über bestimmte spezifische Kenntnisse und Fähigkeiten verfügen. Eine davon ist die reflexive Fähigkeit, die auf unterschiedliche Weise und mit unterschiedlichen Instrumenten erreicht wird. Dieser Artikel präsentiert eine qualitative Interpretation der Antworten der Studierenden, die am Ende eines Semesters in einem reflektierenden Journal verfasst wurden, als Instrument zur Selbsteinschätzung, Selbstreflexion und Feedback zu den Bildungsaktivitäten, an denen sie beteiligt waren. Wir präsentieren anonym die vorherrschenden Antworten für jedes Item. Die Fragen wurden in reflexive Dimensionen des Lehr- und Lernprozesses gruppiert. Basierend auf diesen Antworten haben wir versucht, die vorherrschenden Antworten zu bestimmten Elementen jeder Dimension zu identifizieren. Diese wurden qualitativ analysiert, um die spezifischen Elemente der Reflexion der Studierenden bei der Optimierung eines zukünftigen universitären Bildungsprozesses zu nutzen.

\section{Introduction}

Students need personal autonomy and control over their learning activities. By learning autonomously, students assume a form of study in which they take the initiative to learn, with or without the help of others (teachers or group colleagues), to plan, lead and evaluate their learning activities. This is selforientation, as a personal attribute or quality, through which the subject of learning assumes his responsibility for the various decisions associated with the learning efforts.

By accepting reflection as one's activity and as an equally important element in self-evaluation, evaluation becomes a formative one. This will ensure a permanent reporting of the students' results (knowledge, skills, competencies) to the training objectives (of the program/discipline) and a permanent reconsideration of them in terms of personal success.
The strategies and types of evaluation used in the university process must be selected in such a way as to correspond to the formative character of the program, but also to the needs of acquiring specific competencies of self-learning and self-reflection and feedback.

\section{Theoretical background}

Self-directed learning is an independent and selfprojected activity, which is individually finalized (Knowles, Holton \& Swanson, 1998; Hiemstra,1976). In the literature various terms, concepts, definitions, and studies associated in some way with self-direction in learning are used by different authors (Hiemstra, 2004; Canipe \& Fogerson, 2006). In the following and centered on this study's goals, we will present some approaches and relationships as fundamental 
approaches needed for understanding the process of students' self-reflection process.

In this regard, the role of the teacher is very important and consists in familiarizing the student with different activities and learning styles proposed by him, in an appropriate learning environment. So, teachers must change the teaching process from 'the one with power' to 'the one with shared power', which supports self-directed learners to be active participants rather than passive recipients of knowledge (Sze-Yeng $\&$ Hussain, 2010). The teacher must understand and apply in the educational process the essence of providing opportunities, as well as stimulating the students' inquiring approach and responsibility (Silen \& Uhlin, 2008).

Why is self-directed learning important for students? Because this will be the way to develop abilities to:

- set and impose realistic goals for the learning process. It is very important for ensuring an efficient educational process in which students and supervisors collaborate for alignment of the objectives with desired outcomes, to overcome different issues or challenges - (Larsen et al., 2017).

- look for the necessary information in different resources (library, Internet, various database, etc.). The student could develop their competencies through self-directed learning, involving significant changes in controlling their learning processes (Mok \& Lung, 2005, p. 35). Students with higher academic success were found to have significantly higher self-directed learning skills (Tekkol \& Demirel, 2018).

- activate during the study (learning) certain abilities and skills that they already possess and through which they make new acquisitions. The outcomes for learners who embrace self-directed learning are many, both for the learners and for the professionals (Patterson, Crooks \& Lunyk-Child, 2002).

- be aware of what and how much they know, on the one hand, and what and how much they could know, on the other hand. The students acknowledge the information/learning task and how they understood them, as well as what and how much of it was assimilated (learned). This means that students reflect on their acquisitions. Because that self-directed learning propensity was found to be significantly related to the transformation of students' learning process in the direction of the reflective mode, the student became an active reflective participant (Hutto, 2009).

- know how to be self-motivated (to be aware of their interests, aspirations, goals) and to be emotionally involved in the learning process. This fact demonstrates that certain types of motivational beliefs help to promote and sustain self-regulated learning. The usage of various cognitive and self-regulatory strategies in the learning process demonstrates the involvement of a certain level of engagement (Pintrich, 1999).

- choose and use the most appropriate learning strategies to achieve their goals. The teacher must build and use teaching methods and materials that support the development of students' acquisitions, to achieve the specific skills for their discipline. However, we frequently find the following situation: the university professor considers that the student already has these autonomous learning skills and requests, consequently, to solve some concrete tasks, without ensuring that the students can solve them. For example, M. Yasmin et al. mentioned in their article (2019) the necessity that learning strategies and skills necessary for selfdirected learning transition may be taught to students within course content or in the form of pre-session workshops.

- monitor, control and evaluate their facts and actions, take measures of self-mediation and selfcorrection, in other words, self-regulating their activity. In this process, students take control of their learning and create plans and strategies to achieve desired goals (Jackson, 2004; Van HoutWolters, 2000).

A teacher at tertiary level must build and use teaching methods and materials that support the training and development of these student acquisitions and abilities, to achieve self-directed learning. In this respect, he/she supports, guides, explains, and exemplifies the curricular contents involved in experiential learning; provides self-directed learning tasks; provides continuous monitoring and feedback on student learning activity and invites the student to reflect and to make self-evaluation.

Of course, self-learning is completed by selfassessment. In the literature are mentioned some relevant writings from educational psychology and psychometrics to define the need for a better understanding of accuracy in self-assessment (Brown, 
Andrade \& Chen, 2015). Self-assessment accuracy is done also by the systematic and continuous activity of monitoring and evaluating the own assessment process to obtain performances corresponding to the learning needs and an optimal motivational level (especially intrinsic motivation). More specifically, the objectives of self-assessment are pragmatic ones and refer to the identification of difficulties or threats that may disrupt the specific learning activity and also lead to a greater level of student independence in assessing their performances (Daniel, 2001).

The results of this consist in acquiring from the gained experience some optimizing perceptions for the subsequent learning activities and, last but not least, personal development or, even personal change, if necessary.

So, the reasons that determine the students to integrate self-assessment in their learning activities are also varied: finding the degree of achievement of the objectives proposed by the teacher or those established by each at the beginning of the training program or the beginning of each training sequence, the desire to selfknowledge and self-realization and not least the improvement of one's learning activity. Of course, not all students are motivated by such intrinsic reasons, some are guided in the activity of learning by extrinsic reasons such as advancement in the job, professional retraining, access to greater financial resources, etc. Is often difficult to convince about the need to supplement the teacher's assessment with personal self-assessment.

Often, the student invokes the fact that he/she does not know how to solve the learning problem situations or, quite frequently, he/she does not even make this difficulty known to the teacher or the workgroup. One of the common causes may be that the self-assessment process is not always doubled by self-reflection on that process.

Regardless of the motivation that guides students to achieve an effective self-assessment, it must go through certain stages and overcome certain obstacles: the mentality of the student who is not open to change and taking responsibility for learning (considers that this responsibility belongs to the teacher), the resistance of the student who invokes reasons such: I do not have time, not everyone wants self-assessment in evaluation and inexistence of personal values as a benchmarks in self-evaluation (different from individual to individual), etc.
On the other hand, student self-assessment, defined as a dynamic process in which students selfmonitor, self-evaluate, and identify correctives to learn, is a critical skill that enhances student motivation and achievement (McMillan \& Hearn, 2008). The final result of self-assessment is selfreflection, then extended to the student's ability to transfer the conclusions of self-reflection into the learning process and later into workplace activities to improve the personal work style. We observe, therefore, that self-evaluation is a cyclical process that has as a source and at the same time as finality, the practical dimension of learning. More specifically, self-assessment starts from the students' pragmatic experiences and aims at better coordination of the student's reflection on their learning process.

The cyclical nature of self-assessment revealed by C. Rolheinser (1996) in the model proposed for students refers to the fact that self-assessment being performed objectively, automatically determines the setting of higher goals, which requires effort from the student. As a result of their effort, knowledge is assimilated and certain competencies are formed. The student assesses his/her results in terms of personal value judgments and self-awareness. If the established goals are achieved, their self-esteem and personal involvement in self-assessment automatically increase.

Feedback on the teaching process and reflection on one's activity are constant approaches in formative assessment and are specific to the teacher and the student in the self-assessment process. There are many achievements for students who are self-aware in the educational process: grow the students' confidence, justification and assumption of their learning actions and the whole process of decision-making (Glaze, 2002); assures that students become professionals in self-monitoring and be able to identify multi-faceted problems and implement solutions in solving problematic situations (Tate, 2003); is a fundament for achieving higher levels of learning and full appreciation of complex concepts and problems (Kanuka, 2002); represents a mobile for active learning and involvement in the learning process through seeing things in a new way or to transform their perspective (Ruland \& Ahern, 2007).

Critical reflection encompasses different purposes for students' learning process (thinking, learning, and assessment of self-systems), manifests different forms of reflection (personal, interpersonal, contextual, and 
critical) in the educational process, and uses the different instruments for reflexive writing (reflective journals, reflective notes, reflective portfolios, etc.) (Smith, E., 2011).

The learning journal is a collection of notes, observations, thoughts, or other relevant materials built over a while, usually accompanying a student's period of study. Reflective learning journals support students in organizing and consolidating critical thinking by reflecting on newly learned ideas, concepts, abilities, and attitudes. They give the teachers an image of the evolution of students' learning, but also on their teaching activity, automatically becoming a useful feedback tool.

So, the benefits for using the reflective journal in the educational process are multiple as: assure confidentiality, a safe environment, and reassurance for the student which were extremely important for self-reflection (Chirema, 2007); promotes professional development, allowing students to establish connections between the personal self and the professional role that they assume; stimulate personal reflection and optimization of teaching process (Gillis, 2001); can form a means of communication between students and teachers, promoting a new approach to teaching (Phelps, R., 2005); it allows students to recognize and assume their strengths and weaknesses in the educational process (Glaze, 2002); helps students to evolve professionally, but also to set goals and ethical concerns regarding different ethical issues (Hubbs \& Brand, 2005).

The reflective journal is also a feedback instrument. Giving feedback in reflective journalkeeping, this assessment modality has a powerful influence in fostering reflection during the semester (Pieper et al., 2021). Thus, the reflective journal reveals how students think about what and how they have learned and facilitates the integration of new acquisitions into their knowledge system. Also, it is a mirror of what and how has been developed in the teaching process.

\section{Research methodology}

In this research, we aimed to make a qualitative analysis on students' reflection on their learning activity and also on the teaching activity (selfreflection and feedback).

The literature review presented by M. E. Langley, \& S. T. Brown, (2010) reveals that this kind of research can be structured on some dimensions, which showed some specific results. Starting with these, we created a learning journal with 12 questions (Appendix A). These items are distributed as following 3 questions for each dimension mentioned by relevant authors as benefits of the completion of the learning journal: professional development (1-3), personal development (4-6), empowerment (7-9), and facilitation of the learning process (10-12).

The group of the investigation consisted of 50 second-year students from the Teacher Training Department in Timisoara. Students filled in this reflective journal at the end of the semester, its completion being optional. The answers presented below are anonymous.

\section{Results}

The students' answers to question 1 revealed that this discipline supported them a lot in ensuring a theoretical-pragmatic foundation for the future teaching profession. Here are some of the students' answers:

I have reached an enormous amount of knowledge that I will use in my career as a teacher.

The subject of this discipline is focused on my training for becoming a specialized teacher.

It taught me how to approach teaching and students in my future professional career. It was the beginning of my training for the teaching profession by providing me with a wealth of information and materials that will be useful to me in the process of building a teaching career.

I consider that this discipline helped me a lot in my training for the future teaching profession. He provided me with the theoretical knowledge necessary for conducting teaching and evaluation in the classroom.

It gave me a better understanding of the activities performed by the teacher and the official documents that guide them.

I realized that it is not as easy as it looks from the outside...there are many steps to follow to become a teacher in a school...

Pedagogy II is the foundation I need to succeed in this future career.

I consider that I have acquired useful skills and concepts for the teaching profession, which I will use in the future profession. 
I have learned certain methods, certain teaching strategies, which will help me a lot in my future teaching career.

Also, some students considered that the discipline has supported a better understanding and approach of the teacher-student relationship, both in the teaching process in which they are engaged and in the training for the future teaching career:

In addition to all this, I learned that the relationship between a teacher and his students is much more important than all the theoretical notions.

It taught me what the teacher has to do every day and to pay close attention to my future students.

I learned that without a combination of knowledge, patience, understanding, and perseverance, I could not be a really good teacher.

With the help of this discipline, I understood that a teacher must be supportive of the students and the most important element for a collaboration between the two is communication.

It helped me to understand that there are several types of teaching depending on each individual and the possibility of adapting each method to each person, according to students' needs. I developed the ability to understand the students better.

I understood much better how I could relate to students' needs, how I could improve the teacherstudent relationship and how to focus teaching on students, and how to provide them with information that would be scientific and attractive at the same time.

Last but not least, we consider it extremely important that students have identified the contribution of the discipline to their personal development, despite the theme of this question. The answers are varied and denoted that the students consider personal qualities as teachers' qualities. They mentioned aspects such: communication, development of critical thinking and reflexivity, training and development of individual study skills, aspects of motivation and personal will in the learning process:

This discipline helped me to develop my communication style because I am a little more introverted when it comes to speaking in public. After this semester, I learned that I need to communicate more and have more confidence in my abilities.
... and it helped me realize that there is no wrong answer in the educational process, but it sometimes needs to be "polished" like a diamond.

I consider that I have evolved from some point of view.

What I noticed more pronounced was that I developed my horizons of thought and I did not have any impasse from which I could not get out. I can call it critical thinking and self-reflection.

.... not to be afraid to express my personal opinion on a given topic.

The teacher supported me by the simple fact that we were taught to work and put our soul into what we do.

This discipline taught me that, even if at the beginning this job will be difficult, I must always fight to become even better, because it is possible.

This discipline helped me get closer to my personal development goals.

... and that I can make a change on my own...

For question 2, some of the students specifically mentioned certain curricular contents that will support their subsequent teaching process for the specialized disciplines, but also certain strategies that they can apply to the learning process of the other faculty disciplines (methods, teaching aids, online applications).

During this semester, I mastered the school curriculum much better. I also managed to understand exactly how a lesson project is done and what the types of lessons are. I think that these aspects will help me to teach in the future the disciplines Romanian and German.

The teaching methods that I will apply to Romanian and French.

I have acquired a good knowledge of communication and skills on how to share scientific information, which will help me especially in the discipline of Romanian language and literature.

The teamwork used in this discipline will be very useful for me in the Geomorphology laboratory.

Watching movies to understand the subject matter. For example, for the subject "Contemporary Russian Language" watching movies will help me to understand the grammar of this complex language, but also the culture of these people. 
I also started using the mapping platforms for the Effective Communication discipline and the Jam board for the Complex Analysis discipline.

In the students' answers, it frequently appeared that critical thinking and reflection, as skills developed in this discipline, will be useful in learning in different disciplines.

It helped me develop my critical thinking. This "tool" will be useful, especially in English literature where critical thinking has the main role.

Undoubtedly, the critical thinking and selfreflection that I gained during Pedagogy II. For example, in Comparative literature and in Romanian literature, where I have to interpret and reinterpret or focus on a certain keyword or clue, these two, reflection and critical thinking are a "must-have". Self-reflection is the first step towards an arguing of something and it certainly helped me, helps me, and will help me.

I will apply critical thinking and reflection on all the subjects I will study, taking into account the fact that they are interdependent. What I will learn represents somehow a consolidation and updating of what I have already learned, having the ability to do connections and reflection in my learning process.

We have identified several answers that mentioned the ability to "learn to learn" as an essential acquisition that can be used in any discipline. These skills are mentioned as certain specific elements: learning plan, systematic approach of the learning process, etc.

Most of all, I was taught to learn. I mean, at first, I learned everything that was on the platform, but I didn't realize that I missed a lot of things and I'm not concrete.

We have undertaken a series of tactics that make the learning process much more useful and enjoyable.

The seriousness with which I will perform my tasks, the organization of my learning time, in a useful way.

Most of all, I will be able to develop and use a practical learning style because I have found that it helps me to retain information, much better than the visual or auditory style helped me.

I will try schematically to highlight both the main ideas and the important notions in a certain text. I believe that I have learned to manage my learning more effectively through the strategies I have learned.

Self-assessment was a personal ability that was also mentioned by several students:

Self-assessment was a very important factor, which I managed to develop in this discipline.

The importance of self-assessment. I would like to apply this to all disciplines because I will be able to monitor my progress along my learning process.

I have gained self-evaluation techniques that will be usable in my educational process and my future exams.

The most important aspect mentioned by students (question 3) was the teacher-student relationship, as a good practice model for their professional development. In the students' answers, the most common are those that appreciate the use of open communication model, based on permanent understanding and support offered to the learner:

... a true connection with students and how teachers were attracting students to the discipline through its passion.

The interaction, the methods used, as well as the explanations, for me was a model for managing the learning situations proposed to the students.

The equal treatment and attitude towards all.

...to listen to the students, to give emotional support, to create a connection between me and my colleagues, to make sure that all the students have gained the best possible results.

...humanity, a vulnerability that, without being annoying, makes us feel connected. Sometimes we need a dose of humanity, feelings... the feeling (and the reality) that someone is there with us, next to us, like us... I must always support students to motivate them to become better because she did it with us!

Empathy is a quality that I will take with me in the classroom.

To pay as much attention as possible to my students... a good relationship with them, in the benefit of both parties.

She wanted to get out the best of us, and I think she succeeded.

The importance of the connection between students and teachers, for a better understanding. 
They were mentioned as models of good practice also different teaching strategies or particular elements of it: teamwork, worksheets, how to structure courses:

The team exercises and the team project. These helped us to develop our teamwork skills which I will also apply in my future teaching profession.

The way of working in a team.

I learned how to stimulate the student through different worksheets.

I had a good example of structuring and organizing the lesson, all courses and seminars being interactive; how to discuss /remedy problems.

Several responses considered feedback and reflection as important models for students' professional training:

Feedback on the partial assessment, because knowing that you did right or wrong is not enough, you need to know what you did or did not do well and why.

I also noticed the verbal feedback after each student's response and I think that had a positive effect on the students' development. The correctness and professionalism of the final assessment and the permanent feedback on students' learning activities.

It is very important in the teacher-student relationship to have such a good practice based on objectivity in the assessment process and in the learning process.

The opportunities of the students to reflect on the learning activity.

For question 4 , the students were mentioned most often as strengths their personality attributes such as:

... creativity, the fact that I quickly grasp the meaning of things, without memorizing mechanically.

Being creative in solving certain requirements.

.... the fact that I am a person that is trustful to do its tasks in time.

Conscientiousness, punctuality, respect, adaptability, determination.

Ambition, perseverance, determination.

Several students also mentioned the communication and interaction with other people, as their strengths used in the educational process:
My oral and written communication, the way that I express myself in writing or dialogues with other people.

To collaborate with various colleagues to complete a task.

To socialize during classes, as well as my desire to learn new things.

During these courses, I developed the courage to express my opinion and to say what I think about a certain subject.

The ability to work in a team during the seminar.

Attention and teamwork.

I was able to express my opinion on the covered topics.

The following self-learning skills were mentioned as the singular answer to this question, such:

Tacking brief notes based on a large volume of materials.

My ability to research a certain topic, to synthesize information.

To realize where I am not well-prepared and where I still need to improve my knowledge.

To understand $100 \%$, the material received from the teacher.

The compliance with the proposed deadlines for different tasks.

Regarding the weaknesses (question 5) optimized through the proposed activities of this discipline, most of the answers mentioned an improvement of communication, mostly the oral one:

Communication, socialization, and public speaking.

I corrected my problems by making complete and well-structured oral responses.

Confidence in the possibility of recovering my communication and social interaction.

The difficulty of working in a team.

I like to work confidently and get very involved when I work on something.

My public speaking aptitude it's a pretty strong point of mine.

Because I am a shy person, the interactions through this discipline helped me a lot to have the 
courage to express my opinion without thinking that I will say something wrong or not.

The following are answers that pointed out weaknesses optimized through this discipline, mainly certain personality traits such as patience and selfesteem:

This discipline helped me to be more patient with the people around me.

I think that this discipline, first of all, supported me to be more patient.

To not be so critical of me.

To not underestimate me, to have more confidence in myself.

I corrected self-confidence through these interactions.

Only a few students mentioned as important the correction of aspects related to the learning process itself such as:

Sometimes I have to work harder and strive to research certain issues in more detail, to find the right solution, without stopping at the first result found.

A better understanding of the materials.

Many students repeated the answers regarding the acquired professional skills (question 6) and didn't focus on the acquisitions valuable for their personal development. We have selected some of the few answers offered to this question:

Supported me in dealing with the people I interact with within different fields.

The learning experience in this discipline helped me a lot in my personal development because I became a much more attentive person, more focused on duties. I have to fulfill and be much more attentive to the essential aspects of content.

I will be able to be a much more orderly person, who will be able to cope with any situation. All of these are some elements that will help me to be a good teacher, to be closer to the students.

Both from a professional and personal point of view, I am convinced that my interpersonal communication skills will be very helpful in the future teaching process.

Mostly, the learning styles used by students in the learning process is the visual style and the auditory one (question 7).
I combined several learning styles, but I mainly used the visual one. I made colorful diagrams and figures that summarized the main points of the courses, then I read the courses based on this skeleton of the information.

The auditory and the visual styles.

I used the visual learning style in this discipline, because the PowerPoints from the courses came in my support, being structured schematically with the help of some figures, for example. I think that in this way my visual memory was used much easier.

I used the auditory style, listening to the teacher's observations, but also the visual style, taking notes from his explanations. These useful explanations helped me to understand the subject matter.

I retained ideas and details through listening and seeing the presented images.

Only a low number of students mentioned that they have not used a specific learning style or different from the one they use commonly in other disciplines.

I can't say that I used a certain learning style.

I learned as I learn in other disciplines.

Most students mentioned in their answers the difficulties related to the curricular contents and its understanding (question 8):

In the beginning, I admit that it was hard for me to adjust to the requirements of the worksheets and this way of interacting ... but along the semester, I started to open up more and I communicated better.

The only difficulty I encountered was the fact that I confused some notions until I understood them well and couldn't make difference between them. Also, some of the concepts were difficult to remember, due to their complex definition.

Also, a few students stated that they did not have difficulties in the learning process, because of the teacher's support:

I did not have difficulties in the learning process, because I always read the courses and the gave information was enough to understand and learn the subject.

I can't say that I had any difficulties. Even though the classes were online, the teachers made sure that the theoretical notions were clearly understood. 
There are a few students who mentioned some difficulties regarding online teaching related to attention and concentration.

I think the biggest difficulty was focusing my attention because sitting in front of the computer for so many hours distracted me and made me tired.

I quickly lost my concentration in the online process.

The predominant answers for question 9 were related to the need for change involvement and communication in the teaching process.

If I could change anything, I would have to be more present mentally, not just physically. I want to improve this because it can be a great advantage to say where you did not understand and to communicate more.

If I could change something, I would most likely do it in a way that made me more communicative.

I would change my implication in the course, I would try to get more involved in the activities.

About the same proportion, students mentioned aspects related to their learning style that needs to be changed/ optimized:

I would change my way of learning, I would like to not learn mechanically, I would like to start learning more logically.

I would try to take more notes because in the online learning process I did not write much.

I would probably try to read more in the first part of the semester, to shorten the period of accommodation with the curricular contents.

Mostly the human external factors were mentioned as supports for the students' learning (question 10):

The teacher, the communication model, the relationship with students.

The responsibilities that I have in this discipline, supported by the attitude and guidance of the teachers.

The warm and open attitude of the teacher, who was always there to answer any questions we might have and who explained to us each course. So, that was how I could better understand the contents and my responsibilities.

The good teaching model of the teachers.
The course teacher is the one who helped me to realize the responsibilities better in this discipline, through the very coherent explanations, the involvement that he had, and the patience that she showed during the semester.

Some answers punctually mentioned the support brought by the didactic strategy used, especially the didactic means:

The means provided by the "google meet" platform, for example, the digital whiteboard, where I was able to collaborate with my colleagues to accomplish a proposed task.

The course supports.

The team activities, the Padllet, and the Jamboard.

The team activities helped me a lot.

Only a few students mentioned the personal skills that supported their responsibility:

The fact that I know how to order the responsibilities according to their importance was very helpful.

The fact that I was present at both courses and seminars helped me a lot.

My self-determination and personal motivation to achieve everything, with hard work and implication, even with certain sacrifices.

The relationship with colleagues and teachers was considered good and very good. The students did not make proposals regarding the changes that could be implemented in a future relationship (question 11):

Even if this semester was different, this did not stop me from having a very good relationship with both my colleagues and the teachers.

I consider that I related well with other colleagues and teachers. At the seminar, it was a smaller group and I was able to relate much easier with the participants.

I learned how to cooperate well with my colleagues.

I considered my colleagues like my family, despite the online educational process. We had a very good relationship that should not be changed.

Most students said that they efficiently used the learning time for this discipline and offered motivation for the answers (question 12). 
Yes, I always divide my time in such a way that I can solve all my homework on time.

I consider that I used my time efficiently because I managed to fulfill all my duties on time.

I consider that I used my time efficiently because I gave myself a certain time interval for a certain activity and I paid maximum attention in that interval.

I think so. Within this discipline, I received a lot of understanding and I met teachers who are dedicated to this profession. Each time spent in this activity represented for me a new stage of learning and advancement.

A few students were critics of their time management:

Certainly, my time could be used a little more efficiently in my activities.

I consider that yes, even if not always to maximum potential.

I think my time could have been used more effectively, but overall, I'm happy with the way I've managed it. I've never had any serious problems that I didn't solve in a good manner. I was able to find a solution for any problem at an optimal time.

\section{Discussion and conclusion}

Teacher learning and development is a complex process that brings together a host of different elements and is marked by an equally important set of factors (Avalos, 2011). The respondent students pointed three important dimensions approached during this discipline, as fundamentals for their future teaching career: the importance of the theoretical-pragmatic foundation; the relationship with students, and their personal development. We consider that their responses revealed the importance given by them to the theoretical framework of the teaching profession as a solid base for them, as future teachers. Also, it is interesting that they considered the understanding of how teacher-student relationships function to be very important for their professional foundation. In addition to Wubbels, T., \& Brekelmans, M. (2012) students mentioned that communication with students must be characterized by helpful/friendly and understanding behaviors. Their dominant responses in this direction showed us that they considered very important the content and the model of the teacher-student relationship for better communication and preparation for an effective and future teaching career. Also, many answers affirmed that they gained some personal abilities which sustained them in their personal development. We observed that communication is frequently mentioned in students' answers, important for a future individual, not only for a teacher. Also, the development of critical thinking and reflexivity, training, and development of the individual study is mentioned by the students as being necessary abilities for in-depth learning and a would-be student-centered teacher.

The reflective journal is an instrument that also supports teachers to know the impact of their teaching in their learning in general and can serve as a selfassessment tool to evaluate educational philosophy and instructional approach in the classroom (Hume, 2009; I. Lee, 2008). All of these have an impact on the future learning of students in other educational contexts (disciplines or other types of activities).

Teaching and teaching development involve more than content, methods, and outcomes: being a teacher involves more than choosing content, employing appropriate methods, and aiming for appropriate learning outcomes (Åkerlind, 2004). We observed in students' journals that they used some educational strategies in learning, feedback, and self-evaluation used in other disciplines and that is proof that the teaching process was a reflective one. Also, the educational strategies used in this teaching process was considered by the respondents as a very important tool for their professional training as a future teacher. Feedback and reflection were mentioned frequently as very important when teachers try to support them in their professional development.

R. Edmunds and T. Richardson, (2009) had not found evidence for real changes in students' conceptions of learning, approaches to studying, personal development, and their change across their degree programmers. In our study, we considered it very important that students do a self-assessment regarding their strengths that supported the educational process, their weaknesses that were optimized in the educational process, to define their personality, but related to the educational process in which they were involved. This is what we see also when the students indicated how to use this learning experience for their personal development - their responses were related to personal professional development not on their personal development. This may suggest that students may not or do not want to present particular aspects of 
their personality, only those that are present in the teaching process.

Personal agency means that students exercise internal control, responsibility, and efficacy in learning and regulating their actions (Deci \& Ryan, 2002). So, personal agency is very important in the process of empowerment in the educational process. Regarding this, students reflected on their learning style in many answers given for this dimension. Although, some of them considered that they do not need to change something in their learning style or attitude for the educational process, probably because they declare that they didn't have difficulties in learning this discipline. A part of them considered that they have to change some aspects regarding their learning style. In the whole process of self-reflection and selfresponsibility, it is very important to assume what are the difficulties which could be a gap between them and their empowerment process and how or with the help of who they will exceed them. In this respect, we provoked the students to answer also to the questions regarding who facilitated them in their learning process and how was their relationships with teachers or colleagues. Again, from their answers, we showed that the relationships with the teacher as a facilitator of learning (its personality or teaching techniques) and with the colleagues (as coworkers) were considered good modalities for supporting their learning.

Only a few students were critical of their time management and the rest were satisfied by it. In the literature, it was suggested that the relationship between personality and academic performance is mediated by study attitudes and habits such as time management practices (Credé \& Kuncel, 2008). This is very important also, to sustain the teaching process and indicate their responsibility and self-management in the educational process.

In conclusion, the use of the students' learning journals in the educational process at university offers some personal and professional information about the respondent and the teacher. Also, the learning journal invites both participants to reflect on their implications and actions during the process and the results determined by these. The results could be manifested on students' learning or the teaching process and invite the responsible for each process to gain new strategies, better ones, for the next educational process in which will be involved.

\section{Appendix A.}

\section{Student's learning journal}

\section{PROFESSIONAL DEVELOPMENT}

1. How did this discipline support me in my professional development for the teaching profession?

2. What will I be able to capitalize mostly from this discipline in learning other disciplines? Please mention the discipline/disciplines and the aspects possibly to be capitalized.

3. Which part of the good practice models offered by the teachers will be most useful in my professional training as a future teacher?

\section{PERSONAL DEVELOPMENT}

4. What were the strengths that I valued in the interactions/ activities of this discipline?

5. What weaknesses were corrected through the interactions/ activities of this discipline?

6. How can I use this learning experience for my personal development in the future?

\section{EMPOWERMENT}

7. Did I use a certain learning style in the learning process of this discipline?

8. What difficulties did I encounter in the learning process of this discipline?

9. If I could change something in my attitude on this discipline, what would I do?

\section{FACILITATION OF THE LEARNING PROCESS}

10. What helped me better realize my learning responsibilities for this discipline?

11. How well did I relate to the other colleagues/ teacher? How could I have related otherwise?

12. Did I use my time effectively for the discipline's specific activities?

\section{Authors note:}

Carmen Maria Țîru is a lecturer at The Teacher Training Department from the West University from Timisoara. The main areas of my professional interest are general pedagogy, adult education, and intercultural education. My scientific activity recommends me as co-author of several books and book chapters, support courses, a practice guide for 
pre-primary education. Also, I have published some articles in educational journals, in the country and abroad. I was involved in several programs or projects which offered professional training programs in the field of pre-university and university teaching as: trainer, educational expert, or research member of several research teams by national projects.

\section{References}

Akerlind*, G. S. (2004). A new dimension to understanding university teaching. Teaching in higher education, 9(3), 363-375.

Avalos, B. (2011). Teacher professional development in teaching and teacher education over ten years. Teaching and teacher education, 27(1), 10-20.

Brown, G. T., Andrade, H. L., \& Chen, F. (2015). Accuracy in student self-assessment: directions and cautions for research. Assessment in Education: Principles, Policy \& Practice, 22(4), 444-457.

Canipe, J. B., \& Fogerson, D. L. (2006). The literature of self-directed learning: Dissertations. International Journal of Self-directed Learning, 3(2), 34-44.

Chirema, K. D. (2007). The use of reflective journals in the promotion of reflection and learning in post-registration nursing students. Nurse education today, 27(3), 192-202.

Credé, M., \& Kuncel, N. R. (2008). Study habits, skills, and attitudes: The third pillar supporting collegiate academic performance. Perspectives on psychological science, 3(6), 425-453.

Daniel, R. (2001). Self-assessment in performance. British Journal of Music Education, 18(3), 215-226.

Deci, E. L., Ryan, R. M. (2002). Handbook of selfdetermination research. Rochester, NY: The University of Rochester Press.

Edmunds, R., \& Richardson, J. T. (2009). Conceptions of learning, approaches to studying and personal development in UK higher education. British Journal of Educational Psychology, 79(2), 295-309.

Gillis, A. J. (2001). Journal writing in health education. New Directions for Adult and Continuing Education, 2001(90), 49-58.

Glaze, J. E. (2002). Stages in coming to terms with reflection: student advanced nurse practitioners' perceptions of their reflective journeys. Journal of advanced nursing, 37(3), 265-272.

Hiemstra, R. (1976). Lifelong learning: An exploration of adult and continuing education within a setting of lifelong learning needs. IACE Hall of Fame Repository.

Hiemstra, R. (2004). Self-directed learning lexicon. International journal of self-directed learning, 1(2), 1-6.

Hubbs, D. L., \& Brand, C. F. (2005). The paper mirror: Understanding reflective journaling. Journal of Experiential Education, 28(1), 60-71.
Hume, A. (2009). Promoting higher levels of reflective writing in student journals. Higher Education Research \& Development, 28, 247-260.

Hutto, S. T. (2009). The relationships of learning style balance and learning dimensions to self-directed learning propensity among adult learners. The University of Southern Mississippi.

Jackson, N. (2004). Developing the concept of metalearning. Innovations in Education and Teaching International, 41(4), 391-403.

Kanuka, H. (2002). Guiding principles for facilitating higher levels of web-based distance teaching and learning in post-secondary settings. Distance Education, 23(2), 163-181.

Knowles, M., Holton, E. F., \& Swanson, R. A. (1998). The adult learner: The definitive classic in adult education and human resource development (5th ed.). Houston, TX: Gulf Publishing Company.

Langley, M. E., \& Brown, S. T. (2010). Perceptions of the use of reflective learning journals in online graduate nursing education. Nursing education perspectives, 31(1), 12-17.

Larsen, D. P., Wesevich, A., Lichtenfeld, J., Artino Jr, A. R., Brydges, R., \& Varpio, L. (2017). Tying knots: an activity theory analysis of student learning goals in clinical education. Medical education, 51(7), 687-698.

Lee, I. (2008). Fostering preservice reflection through response journals. Teacher Education Quarterly, 117139.

McMillan, J. H., \& Hearn, J. (2008). Student selfassessment: The key to stronger student motivation and higher achievement. Educational horizons, 87(1), 40-49.

Mok, M. M. C., \& Lung, C. L. (2005). Developing selfdirected learning in student teachers.

Patterson, C., Crooks, D., \& Lunyk-Child, O. (2002). A new perspective on competencies for self-directed learning. Journal of nursing education, 41(1), 25-31.

Phelps, R. (2005). The potential of reflective journals in studying complexity in action. Complicity: An International Journal of Complexity and Education, 2(10), 37-54.

Pieper, M., Roelle, J., vom Hofe, R., Salle, A., \& Berthold, K. (2021). Feedback in reflective journals fosters reflection skills of student teachers. Psychology Learning \& Teaching, 20(1), 107-127.

Pintrich, P. R. (1999). The role of motivation in promoting and sustaining self-regulated learning. International journal of educational research, 31(6), 459-470.

Rolheiser, C. (Ed.) (1996). Self-evaluation: Helping students get better at it. Toronto: Visutronx

Ruland, J. P., \& Ahern, N. R. (2007). Transforming student perspectives through reflective writing. Nurse Educator, 32(2), 81-88.

Silen, C., \& Uhlin, L. (2008). Self-directed learning-a learning issue for students and faculty!. Teaching in Higher Education, 13(4), 461-475. 
Smith, E. (2011). Teaching critical reflection. Teaching in Higher Education, 16(2), 211-223.

Sze-Yeng, F., \& Hussain, R. M. R. (2010). Self-directed learning in a socioconstructivist learning environment. Procedia-Social and Behavioral Sciences, 9, 1913-1917.

Tate, S. (2003). Educating for reflective practice. The Journal of Alternative \& Complementary Medicine, 9(5), 773-777.

Tekkol, İ. A., \& Demirel, M. (2018). An investigation of self-directed learning skills of undergraduate students. Frontiers in psychology, 9, 2324.

Tutticci, N. F. (2017). Measuring reflective thinking and self-efficacy after high fidelity simulation to optimise the reflective capacity of final year nursing students (Doctoral dissertation, Queensland University of Technology).

Van Hout-Wolters, B. (2000). Assessing active selfdirected learning. New learning (pp. 83-99). Springer, Dordrecht.

Wubbels, T., \& Brekelmans, M. (2012). Teacher-students' relationships in the classroom. Second international handbook of science education, 1241-1255.

Yasmin, M., Naseem, F., \& Masso, I. C. (2019). Teacherdirected learning to self-directed learning transition barriers in Pakistan. Studies in Educational Evaluation, 61, 34-40. 